\title{
Type A aortic dissection: Are we any nearer to taming the beast?
}

\author{
Mazin A. I. Sarsam, MBChB, FRCS, FRCS(ed), FRCSC, EBCTS
}

\author{
From the Department of Cardiac Surgery, St. Georges Hospital, London, United Kingdom. \\ Disclosures: Author has nothing to disclose with regard to commercial support. \\ Received for publication Jan 29, 2018; accepted for publication Jan 31, 2018; available ahead of print March 9, \\ 2018. \\ Address for reprints: Mazin A. I. Sarsam, MBChB, FRCS, FRCS(ed), FRCSC, EBCTS, Department of Cardiac \\ Surgery, St. Georges Hospital, Blackshawe Rd, London SW17 0QT, United Kingdom (E-mail: mazin.sarsam@ \\ stgeorges.nhs.uk). \\ J Thorac Cardiovasc Surg 2018;155:2251 \\ $0022-5223 / \$ 36.00$ \\ Copyright (C) 2018 by The American Association for Thoracic Surgery \\ https://doi.org/10.1016/j.jtcvs.2018.01.062
}

Despite recent advances in treatment, acute aortic dissection remains a devastating medical and surgical emergency associated with high mortality and morbidity. The International Registry for Acute Aortic Dissection registry has reported only a slight decrease in mortality over the last 2 decades, from $25 \%$ to $18 \%$.

In their article in this issue of the Journal, Shen and colleagues $^{2}$ present a study of 169 consecutive patients with type A aortic dissection over a 2-year period (January 2015 to February 2017) who underwent total arch replacement using separate branched graft and stented elephant trunk in addition to ascending aorta replacement. Either the aortic valve was preserved (99 patients) or the root was replaced in a Bental-type procedure (70 patients), and associated procedures were performed as required. The overall mortality was an excellent $7.1 \%$, and approximately $50 \%$ of patients developed respiratory insufficiency in the postoperative period. Factors identified as significant for the development of hypoxia by multivariate analysis included preoperative hypoxia, body mass index $>25$, homocystine level, circulatory arrest time, and plasma transfusion. The study mirrored other reports using the same procedure for acute aortic dissection coming mainly from mainland China, where the incidence of dissection appears to be higher than average. ${ }^{3}$ The development of respiratory insufficiency did not seem to be associated with excess surgical mortality.

The rationale for this procedure is to reduce the risk of reintervention and to obliterate the false lumen. The authors do not describe how they selected their patients, and do not explain whether this is now their standard approach to every aortic dissection irrespective of the tear site, or how the results compare with the traditional approach of ascending aorta and hemiarch in their hands.

Are there drawbacks to this approach? Certainty, it increases the complexity of the operation and prolongs arrest time. In addition, there is also the risk of paraplegia,

\section{References} 2015;66:350-8. Surg. 2017;24:251-6. Surg. 1998;3:37-42. Surg. 2016;50:33-46.

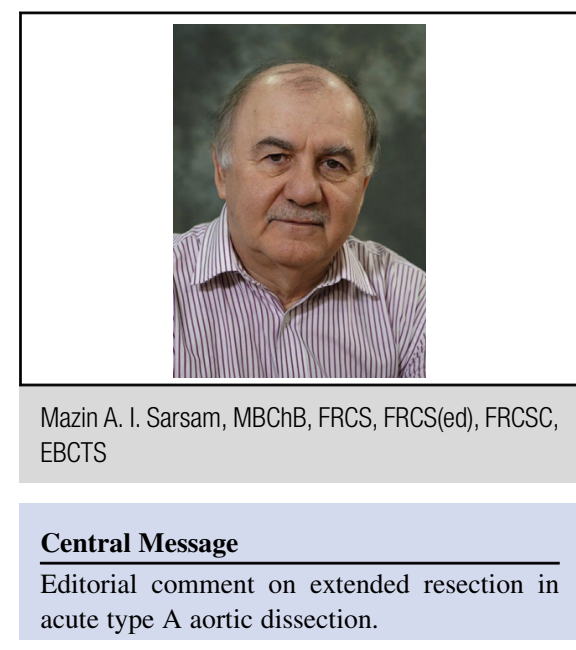

See Article page 2267.

depending of the length of the stent graft. ${ }^{4}$ Before the introduction of frozen elephant trunk, we described a technique of total aorta replacement via median sternotomy by placing a graft within the descending aorta and suturing it to the aorta behind the oblique sinus. This technique was later abandoned except as a bailout procedure for aortic rupture, because of the high incidence of paraplegia. ${ }^{5}$

The priority in dissection has always been first and foremost patient survival. Current data suggest that a more aggressive approach could be applied without higher early perioperative risk, ${ }^{6}$ and that such an approach offers a safe alternative to the conventional approach.

1. Pape LA, Awais M, Woznicki EM, Suzuki T, Trimarchi S, Evangelista A, et al. Presentation, diagnosis and outcome of acute aortic dissection: 17-year trends from the International Registry for Acute Aortic Dissection. J Am Coll Cardiol.

2. Shen Y, Liu C, Fang C, Xi J, Wu S, Pang X, et al. Oxygenation impairment after total arch replacement with a stented elephant trunk for type A dissection. J Thorac Cardiovasc Surg. 2018;155:2267-74.

3. Liu N, Zhang W, Ma W, Shang W, Zheng J, Sun L. Risk factors for hypoxemia following repair of acute type A aortic dissection. Interact Cardiovasc Thorac

4. Flores J, Kunihara T, Shiiya N, Yoshimoto K, Matsuzaki K, Yasuda K. Extensive deployment of the stented elephant trunk is associated with increase risk of spinal cord injury. J Thorac Cardiovasc Surg. 2006;131:336-42.

5. Sarsam MAI. Repair of descending thoracic aortic dissection or aneurysm combined with repair of the proximal aorta via median sternotomy. J Cardiol

6. Takagi H, Umemoto T, ALICE Group. A meta-analysis of total arch replacement with frozen elephant trunk in acute type A aortic dissection. Vasc Endovascular 